\title{
Primitive small cell osteosarcoma of the rib: an exceptional localization
}

\author{
Walid ABID ${ }^{1}$, Meriam Triki ${ }^{1}$, Ghassen BEN HLIMA ${ }^{2}$, Zied CHAARI ${ }^{2}$, Abdessalem \\ HENTATI $^{2}$, and Imed FRIKHA ${ }^{2}$ \\ ${ }^{1}$ University of Sfax Faculty of Medecine of Sfax \\ ${ }^{2}$ University of Sfax
}

February 28, 2022

\begin{abstract}
Small cell osteosarcoma is a rare sub-type of osteogenic malignant tumors. Rib localization is uncommon. Histological examination is an important step to make the difference with similar tumors like Ewing sarcoma. Surgical resection is the unique curative treatment. Prognosis remains poor even with adjuvant treatment
\end{abstract}

\section{ABSTRACT:}

Small cell osteosarcoma is a rare sub-type of osteogenic malignant tumors. Rib localization is uncommon. Histological examination is an important step to make the difference with similar tumors like Ewing sarcoma. Surgical resection is the unique curative treatment. Prognosis remains poor even with adjuvant treatment.

\section{Key clinical message:}

Small cell osteosarcoma is a rare sub type of osteogenic malignant tumors. Difference with other types is retained on histological characteristics. A wrong diagnosis may cause a delay in the management of this type of cancer, mainly on surgical resection which is the unique curative treatment.

\section{INTRODUCTION:}

Small cell osteosarcoma SCO is a rare sub-type of osteogenic malignant tumors, having the same microscopic features as Ewing sarcoma. However, unlike Ewing's sarcoma, it is associated with variable degree of osteoid formation. It occurs, mostly, in the metaphysis of long bones (1). Localization on the rib is exceptional and, to the best of our knowledge, only two cases were presented in the literature.

\section{OBSERVATION:}

An 18-year-old woman who suffered from right basi-thoracic pain and appearance of a swelling at the level of the $10^{\text {th }}$ right rib. Chest $\mathrm{CT}$ showed a heterogeneous hyper vascular mass, located on the 10th right rib and measuring $106 \times 93 \times 110 \mathrm{~mm}$. The mass was heterogeneous with several sites of necrosis. There were 
osteolysis of the rib with bifocal cortical rupture. The mass was in a tight contact with the liver through the diaphragm, which was partially invaded. Surgical biopsy was performed. The mass was composed of small round cells with round uniform nuclei and PAS positive cytoplasm. Tumor cells demonstrate a diffuse membranous CD99 positivity. Desmin, myogenin, chromogranin, synaptophysin and keratin were negatives (Figure 1).

The diagnosis of Ewing's sarcoma was made. The patient received 6 cycles of chemotherapy (Vincristine, Ifosfamide, Doxorubicin and Etoposide). A post therapy Chest CT-scan showed almost the same initial findings (figure 2). Surgical resection was indicated after multidisciplinary team discussion. Resection consisted on a total resection of the 10th right rib with sarcoma, partially extended to the 9th and 11th right ribs and to the diaphragm. There was no signs of direct extension to the liver. Chest wall repair was performed with a polypropylene mesh covered by a latissimus dorsi muscle flap (figure 3).

Postoperative course was uneventful. The pathological examination of the specimen showed a small cell proliferation with foci of lace-like osteoid production (Figure 4). Finally, the diagnosis of a $12 \mathrm{~cm}$ SCO of the $10^{\text {th }}$ right rib, infiltrating adjacent soft tissues, with $20 \%$ of tumor necrosis was established. Surgical margins were negative. Adjuvant chemotherapy with Methotrexate $(12 \mathrm{~g} / \mathrm{m} 2)$ was indicated after multidisciplinary concertation, in association with adjuvant radiotherapy (45Gy). Actually, the patient is well, with a good wound cicatrisation, and no signs of local recurrence.

\section{DISCUSSION:}

SCO is a very rare type of bone malignant tumors arising usually from long bones (femur, tibia, and humerus). Average age is 20 years [6-83 years], but most of the patients are younger than 20 (2). Females were more affected than males, with a sex ratio $\mathrm{M} / \mathrm{F}$ of $4 / 5$ (3). This osteosarcoma rarely affects short $\backslash$ souts bones, and rib-localization is very uncommon. To the best of our knowledge, only two cases were described in the literature $(4,5)$. Table 1 summarizes the characteristics of these two cases comparing to our case.

Histopathological investigation plays an important role in the diagnosis. In fact, small round cell lesions of the bone encompass a large heterogeneous group of tumors and tumor-like lesions. The main differential diagnosis of SCO is Ewing sarcoma. In hematoxylin and eosin colored slides, osteoid production is the characteristic pathological feature of SCO, and may easily distinguish it from Ewing sarcoma. However, in small biopsies, osteoid production can be missing. Thus, immunohistochemistry as well as molecular studies are necessary to make the correct diagnosis. In our case, the tumor was positive for CD99, which is rare but possible in SCO. The immunohistochemical positivity along with the histological features and the cytoplasmic PAS positivity led to the erroneous diagnosis of Ewing sarcoma. A molecular study, excluding the existence of specific sarcoma translocation, like EWSR1-FLI1 fusion-gene could helped to establish the exact diagnosis. Unfortunately, molecular studies are unavailable in our institution. Differential diagnosis includes other tumors, like non-Hodgkin lymphoma, small cell lung carcinoma or rhabdomyosarcoma. Immunohistochemistry is sufficient to exclude these conditions (7).

Surgical resection is the unique curative treatment of SCO (6). Postoperative chemotherapy and radiotherapy may be administered. Vincristine, Adriamycin, Actinomycine D and cyclophosphamide are the most common administrated agents. However, chemo-radiotherapy together is not necessary without the evidence of any malignant cells on the surgical margin or the presence of distant metastasis (7). The 5 year-survival rate for the classic osteosarcoma is $77 \%$, whereas it is $28 \%$ for small cell osteosarcoma $(5,8)$.

\section{CONCLUSION:}

SCO of the ribs is exceptional and should be kept in mind in the management of ribs' tumors. Early diagnosis is important for better-improved prognosis. The integration of clinical, radiologic, pathologic, and 
ancillary test results, including immunohistochemical and molecular results is necessary to establish the right diagnosis. Surgical resection is the only curative treatment and it should be as complete as possible. Adjuvant chemotherapy may improve survival despite the poor prognosis of this aggressive type of bone malignant tumors.

\section{REFERENCES:}

1. WHO Classification of Tumors Editorial Board eds. World Health Organization classification of soft tissue and bone tumors. 5th edition. Lyon: IARC Press, 2020.

2. Martin SE, Dwyer A, Kissane JM, Costa J. Small-cell osteosarcoma. Cancer 1982; 50: 990-6.

3. Devaney K, Vinh TN, Sweet DE. Small cell osteosarcoma of bone: an immunohistochemical study with differential diagnostic considerations. Hum Pathol 1993; 24: 1211-25.

4. Göktürk Fındık, Ersin Günay, Yetkin Ağaçkıran, Koray Aydoğdu, Ertan Aydın, Sadi Kaya. Small cell osteosarcoma of rib: diagnosis and treatment of the rare case. Tuberk Toraks 2012; 60: 172-5.

5. S H Park, I Kim. Small cell osteogenic sarcoma of the ribs: cytological, immunohistochemical, and ultrastructural study with literature review. Ultrastruct Pathol 1999; 23: 133-40.

6. Lushiku HB, Gebhart M. Osteosarcoma of the proximal fibula: report of 3 cases. Acta Chir Belg 1997; 97: 260-3.

7. Dickersin GR, Rosenberg AE. The ultrastructure of small-cell osteosarcoma, with a review of the light microscopy and differential diagnosis. Hum Pathol 1991; 22: 267-75.

8. Glasser DB, Lane JM, Huvos AG, Marcove RC, Rosen G. Survival, prognosis, and therapeutic response in osteogenic sarcoma. The Memorial Hospital experience. Cancer 1992; 69: 698-708.

\section{ANNEXES:}

\section{TABLES:}

TABLE 1: CHARACTERISCTICS OF THE CASES OF PRIMITIVE SMALL CELL OSTEOSARCOMA OF THE RIB

\begin{tabular}{|c|c|c|}
\hline & FINDIK AND AL (2012) & PARK AND KIM (1999) \\
\hline Age & 28 years & 37 years \\
\hline Localization & Left anterolateral region of $6^{\text {th }}$ and $7^{\text {th }}$ ribs & Right $10^{\text {th }}$ and $11^{\text {th }}$ ribs \\
\hline Measurments & Not mentionned & $50 * 50 \mathrm{~mm}$ \\
\hline Preoperative Histological Assesment & Malignant mesenchymal tumor OR osteosarcoma & Not mentionned \\
\hline Protocole Of Chemotherapy & Not mentionned & Not mentionned \\
\hline Survival & 17 months & Not mentionned \\
\hline
\end{tabular}



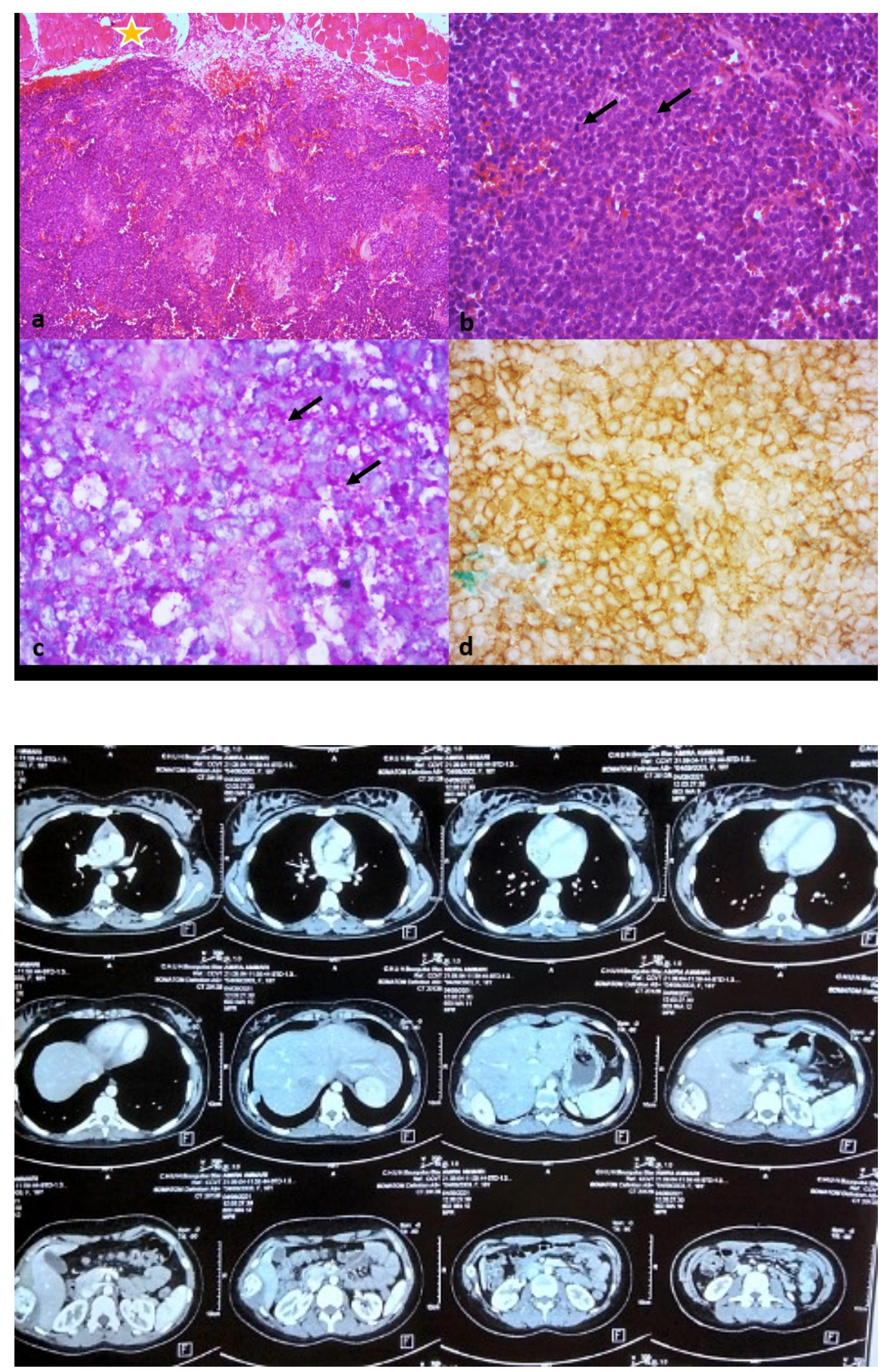

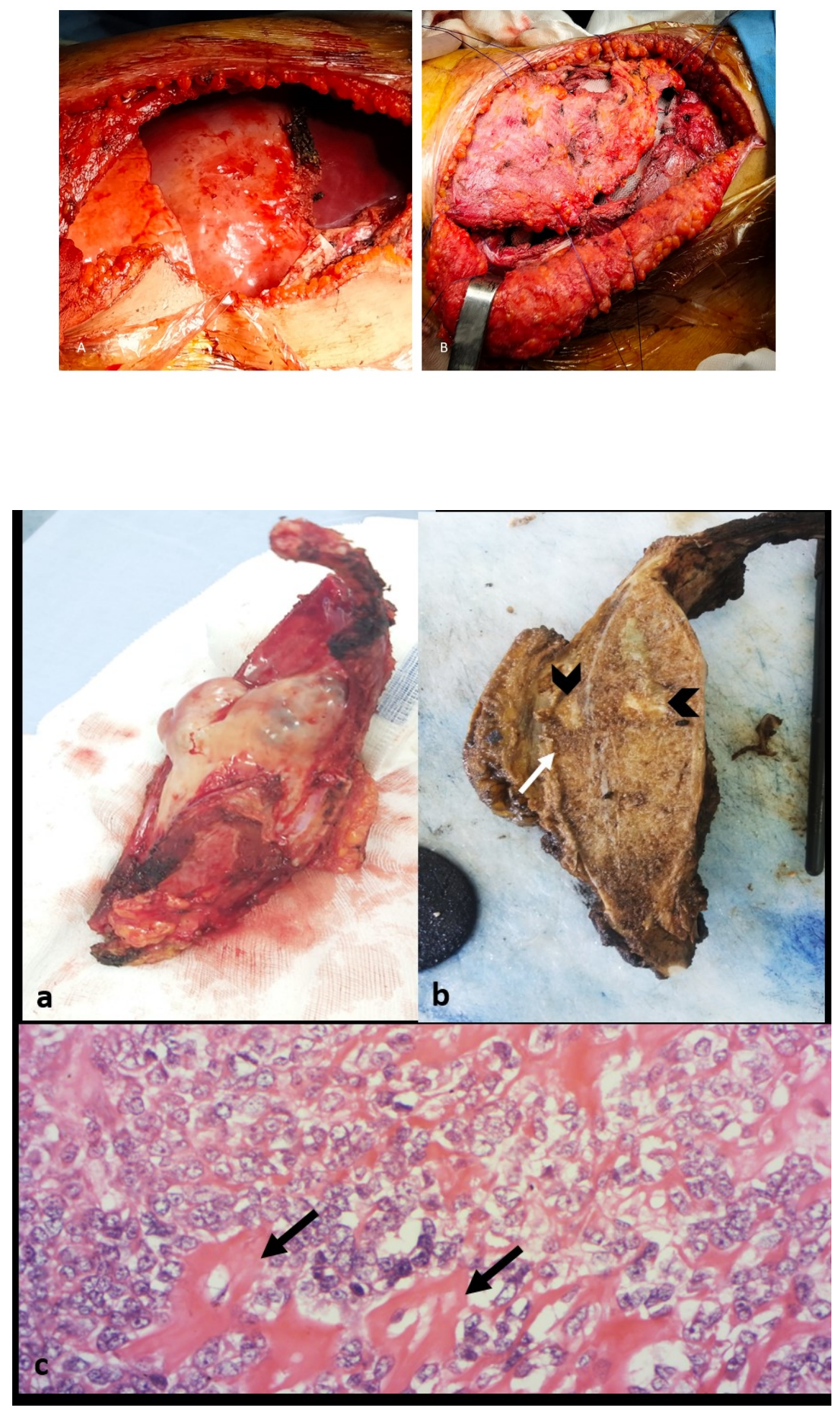